\title{
The importance of del nido cardioplegia solution in coronary artery bypass surgery
}

\author{
Mehmet Bademci ${ }^{1}$, Cemal Kocaaslan ${ }^{1}$, Fatih Bayraktar $^{1}$, Ahmet Oztekin $^{2}$, Bilal Aydin ${ }^{1}$, \\ and Ebuzer Aydin ${ }^{2}$ \\ ${ }^{1}$ Istanbul Medeniyet University Faculty of Medicine \\ ${ }^{2}$ Istanbul Medeniyet Universitesi Tip Fakultesi
}

December 23, 2020

The importance of del nido cardioplegia solution in coronary artery bypass surgery

Mehmet Senel Bademci ${ }^{\mathrm{a}}$ MD, Cemal Kocaaslan ${ }^{\mathrm{a}}$ MD Fatih Avni Bayraktar ${ }^{\mathrm{a}}$ MD, Ahmet Oztekin ${ }^{\mathrm{a}}$ MD, Huseyin Bilal Aydin ${ }^{\mathrm{a}} \mathrm{MD}$, and Ebuzer Aydin ${ }^{\mathrm{a}} \mathrm{MD}$.

${ }^{a}$ Istanbul Medeniyet University, Medicine Faculty, Department of Cardiovascular Surgery, Istanbul, Turkey Corresponding Author: Mehmet Senel Bademci,M.D, Assist.Prof.

Post Publication Corresponding Author: Mehmet Senel Bademci,M.D, Assist.Prof.

Istanbul Medeniyet University Medicine Faculty, Department of Cardiovascular Surgery.

Address: Dr. Erkin St. No:12 Kadikoy, Istanbul, 34722, Turkey.

Mail address: mbademci@gmail.com

Dear Editor;

We read with interest the article by Algarni [1] published entitled "Routine use of del Nido cardioplegia compared with blood cardioplegia in all types of adult cardiac surgery procedures." Algarni KD. Routine use of del Nido cardioplegia compared with blood cardioplegia in all types of adult cardiac surgery procedures. J Card Surg. 2020;10.1111/jocs.15060

In this study; Del Nido cardioplegia group has shorter aortic cross-clamp time for coronary artery by pass graft patients. But there is no sufficient data about the number of distal anastomosis between cardioplegia groups. If there is a significant difference between groups, this answer can change the aortic cross clamp times regardless of cardioplegia.

We congratulate Algarni et al. for their valuable manuscript about cardioplegia solutions in coronary artery bypass surgery. We would like to hear authors' opinion on this matter.

References:

1. Algarni KD. Routine use of del Nido cardioplegia compared with blood cardioplegia in all types of adult cardiac surgery procedures. J Card Surg. 2020;10.1111/jocs.15060. 